\title{
B-lynch suture in the management of uterine atony during caesarean section
}

\author{
Sudha H. C.*, Jaganathan Pairu, Kamalakshi
}

Department of Obstetrics and Gynecology, Bangalore Medical College and Research Institute, Bangalore, Karnataka, India

Received: 22 February 2019

Accepted: 01 April 2019

*Correspondence:

Dr. Sudha H. C.,

E-mail: drhcsudha@gmail.com

Copyright: (C) the author(s), publisher and licensee Medip Academy. This is an open-access article distributed under the terms of the Creative Commons Attribution Non-Commercial License, which permits unrestricted non-commercial use, distribution, and reproduction in any medium, provided the original work is properly cited.

\section{ABSTRACT}

Background: Third stage of labour is still the "sword of Damocle's" hanging above an obstetrician , inspite of today's advanced technologies and personal care. The importance in the management of this deadly stage lies in the anticipation of complications and being quick enough to treat them timely. Hence in such scenarios, B-lynch suture is most popular method in treatment of uterine atony during caesarean section. The objective is to study and evaluate the cases in which the B-Lynch suture was used to treat the uterine atony during caesarean section.

Methods: A prospective randomized study consisting of 50 women with high risk factors for atonic pph during caesarean section were included as study group patients were subjected to B-Lynch suture application when conventional drugs failed to control PPH. Blood loss was measured using a measuring jar. The fall in $\mathrm{Hb} \%$ and the need for blood transfusion, and the need for hysterectomy as a last resort to save the life was evaluated.

Results: The average blood loss was $1490 \mathrm{ml}$ and the majority of patients had reduction in $\mathrm{Hb} \%$ from $1.1-1.5 \mathrm{gm} \%$ $(52 \%), 36 \%$ of the patients did not receive any blood transfusion after B-Lynch suture, and in $80 \%$ of cases hysterectomy was avoided.

Conclusions: Our study shows cases treated with B-Lynch procedure showed that it is an effective method of containing pph. It has the advantage of being applied easily and safely. It should be attempted when conservative management fails and before any radical surgery is considered.

Keywords: B-Lynch, Caesarean section, Hysterectomy, Oxytocics, PPH, Uterine atony

\section{INTRODUCTION}

Postpartum haemorrhage remains a significant cause of maternal mortality and morbidity like hypovolemic shock, anemia, multiorgan failure, coagulopathy, DIC, blood transfusion related complications and hysterectomy lea ding to loss of child bearing potential. In 1997, christopher B-Lynch devised an innovative technique to treat uterine atony and it has been used worldwide widely as a conservative mode of surgical management in atonic PPH during caesarean section. By definition, primary postpartum haemorrhage means loss of more than $500 \mathrm{ml}$ of blood from or into the genital tract in the first 24 hours after vaginal delivery or more than $1000 \mathrm{ml}$ following caesarean delivery. ${ }^{1}$ As the effect of blood loss is important rather than the amount of blood lost the clinical definition which is more practical states Any amount of bleeding from or into the genital tract following birth of the baby up to the end of the puerperium which adversely affect the general condition of the patient evidenced by rise in pulse rate and fall in blood pressure is called PPH". ACOG defines PPH as 'blood loss which decreases the $\mathrm{Hb} \%$ by $1 \%$ or needs blood transfusion'. Hemorrhage occurring beyond 24 hours and within puerperium is called secondary hemorrhage. ${ }^{2}$ 
Even with appropriate management, approximately $3 \%$ of vaginal deliveries will result in severe PPH3. It is the most common cause for maternal morbidity in developed countries and as a major cause of death worldwide globally. It has been estimated the incidence is said to be $3.9 \%$ in vaginal deliveries and $6.4 \%$ in caesarean section deliveries. ${ }^{3}$ It has been estimated worldwide that over 1 , 25,000 women die of PPH each year. ${ }^{4}$ In India, $25.6 \%$ of maternal deaths are due to haemorrhage. ${ }^{5}$

Haemorrhage which persists in spite of conventional treatment will threaten the life of the mother; Where in hysterectomy is resorted to as the last life saving measure. This in turn can be relatively difficult to perform and has the obvious disadvantage of depriving the women of future fertility.

B-Lynch suture originally described by Christopher Blynch in 1997 has gained utmost popularity and has been used as uterine compressive sutures as a conservative surgical measure for treating PPH.

The objectives of this study were to determine the efficacy of B-Lynch suture in the management of PPH secondary to uterine atony. And to assess the advantage of timely application of B-Lynch suture in uncontrolled $\mathrm{PPH}$, thereby reducing the blood loss, decreasing the need for blood transfusions and its associated complications, preserving uterus and obviating the need for hysterectomy.

\section{METHODS}

The present study was conducted at Vanivilas Hospital attached to Bangalore medical College and Research Institute, from January 2018 to December 2018. This is a tertiary care centre, where most of the cases being referred on emergency basis and the data for the study collected by studying patients posted for emergency caesarean section with high factors for atonic PPH. A total 50 patients were included.

\section{Inclusion criteria}

- Prolonged labour

- Obstructed labour

- Antepartum haemorrage(placenta previa/abruption placenta).

- $\quad$ Prolonged rupture of membranes (PROM>24hrs).

- Big baby

- Multiple gestation

- Polyhydramnios.

\section{Exclusion criteria}

- $\quad$ PPH after vaginal delivery

- Secondary PPH

- Patients with bleeding disorders

- Patients with uterine anomalies.

\section{RESULTS}

Table 1 shows distribution of age. 58\% of age belonged to 20 to 25 years with mean age being 23 years. Patients between 26 to 30 years were about $32 \%$. Patients who are less than 20 years and more than 30 years $6 \%$ and $4 \%$ respectively.

Table 1: Distribution of patients according to age.

\begin{tabular}{|lll|}
\hline Age & Number & Percentage \\
\hline$<20$ years & 3 & $6 \%$ \\
\hline $20-25$ years & 29 & $58 \%$ \\
\hline $26-30$ years & 16 & $32 \%$ \\
\hline$>30$ years & 2 & $4 \%$ \\
\hline Total & 50 & $100 \%$ \\
\hline
\end{tabular}

Table 2: Distribution of patients according to gravida status.

\begin{tabular}{|lll|}
\hline Gravida & Number & Percentage \\
\hline Primi & 25 & $50 \%$ \\
\hline G2 & 12 & $24 \%$ \\
\hline G3 & 10 & $20 \%$ \\
\hline G4 & 03 & $6 \%$ \\
\hline Total & 50 & $100 \%$ \\
\hline
\end{tabular}

Table 3: Distribution of patients according to gestational age.

\begin{tabular}{|lll|}
\hline Gestational age & Number & Percentage \\
\hline$<28$ weeks & 01 & $2 \%$ \\
\hline $29-32$ weeks & 04 & $8 \%$ \\
\hline $33-36$ weeks & 08 & $18 \%$ \\
\hline $37-40$ weeks & 34 & $68 \%$ \\
\hline$>41$ weeks & 02 & $4 \%$ \\
\hline Total & 50 & $100 \%$ \\
\hline
\end{tabular}

Table 4: Distribution of patients according to indication for caesarean section.

\begin{tabular}{|lll|}
\hline Indication & No. & $\%$ \\
\hline APH (Abruptio/placentaprevia) & 24 & $48 \%$ \\
\hline Prolonged PROM with failed induction & 10 & $20 \%$ \\
\hline Big baby & 06 & $12 \%$ \\
\hline Obstructed or Prolonged labour & 06 & $12 \%$ \\
\hline Multiple pregnancy & 03 & $06 \%$ \\
\hline Polyhydramnios & 01 & $02 \%$ \\
\hline Total & 50 & $100 \%$ \\
\hline
\end{tabular}

Table 2 shows number of gravid patients. $50 \%$ of patients were primigravida. While gravida2 patients were $24 \%$. Gravida3 and Gravida4 patients were $20 \%$ and $6 \%$ respectively.

Table 3 shows number of patients with different gestational age. Majority of the patients were 37-40 weeks of gestation (68\%). Patients who were between 33-36 
wks are $18 \%$. Patients who were post-dated are $4 \%$ while less than 28 weeks of gestation were only $2 \%$.

Table 4 shows the indications for c. section, APH is the commonest indication (48\%) which includes abruption and placenta previa. Prolonged PROM with failed induction patients were $10 \%$. Obstructed or prolonged labour and big baby were about $12 \%$ each.

Table 5: Distribution of new born weight.

\begin{tabular}{|lll|}
\hline Birth weight & Number & Percentage \\
\hline$<2 \mathrm{~kg}$ & 14 & $26.4 \%$ \\
\hline $2-3 \mathrm{~kg}$ & 23 & $43.4 \%$ \\
\hline$>3 \mathrm{~kg}$ & 16 & $30.2 \%$ \\
\hline Total & 53 & $100 \%$ \\
\hline
\end{tabular}

Table 5 shows majority of newborn babies weighs between $2-3 \mathrm{~kg}(43.4 \%)$, and those weighing more than $3 \mathrm{~kg}$ were about $30.2 \%$. Among the 3 babies of multiple pregnancies, 2 were less than $2 \mathrm{~kg}$. The mean birth weight in this study group was $2.6 \mathrm{~kg}$ ranging from $900 \mathrm{gms}$ to $4.1 \mathrm{~kg}$.

Table 6: Distribution according to blood loss.

\begin{tabular}{|lll|}
\hline Blood loss & Number & Percentage \\
\hline$<500 \mathrm{ml}$ & 0 & 0 \\
\hline $500-1000 \mathrm{ml}$ & 12 & $24 \%$ \\
\hline $1000-1500 \mathrm{ml}$ & 27 & $54 \%$ \\
\hline $1500-2000 \mathrm{ml}$ & 08 & $16 \%$ \\
\hline$>2000 \mathrm{ml}$ & 03 & $6 \%$ \\
\hline Total & 50 & $100 \%$ \\
\hline
\end{tabular}

Table 6 shows the amount of blood loss which was measured in a measuring jar. The minimum blood loss was $800 \mathrm{ml}$ and the maximum being $2500 \mathrm{ml}$ in our study. Majority had blood loss in the range of 1001-1500ml (54\%) which can be attributed to timely application of Blynch suture.

Table 7: Distribution of blood loss according to gravida status.

\begin{tabular}{|llllll|}
\hline Gravida & Number & Mean blood loss & Standard deviation & Minimum & Maximum \\
\hline Primi & 25 & 1420.08 & 393.280 & 900 & 2000 \\
\hline Multi & 25 & 1569.92 & 462.551 & 800 & 2500 \\
\hline Total & 50 & 1495.00 & 428.363 & 800 & 2500 \\
\hline
\end{tabular}

Table 7 shows the blood loss according to gravida status. The mean blood loss in primi was $1400 \mathrm{ml}$ and in multi was $1500 \mathrm{ml}$. The minimum blood loss in primi was $900 \mathrm{ml}$ and in multi it is around $800 \mathrm{ml}$. The maximum blood loss was $2000 \mathrm{ml}$ in primi and $2500 \mathrm{ml}$ in mullti.

Table 8: Distributions of $\mathrm{Hb}$ values.

\begin{tabular}{|lllll|l|}
\hline & Mean & N & SD & $\begin{array}{l}\text { Mean } \\
\text { difference }\end{array}$ & SD \\
\hline Pre $\mathrm{Hb}$ & 9.7 & 49 & 1.0763 & 1.0816 & 0.4803 \\
\hline Post $\mathrm{Hb}$ & 8.6 & 49 & 1.044 & & \\
\hline
\end{tabular}

In Table 8 the mean pre procedure $\mathrm{Hb}$ was $9.7 \mathrm{gms} \%$ and mean post procedure $\mathrm{Hb} \%$ was $8.6 \mathrm{gm} \%$. The mean difference in pre and post procedure was $1.08 \mathrm{gm} \%$ reflecting that timely application of B-Lynch suture reduced blood loss and hence decrease in post procedure $\mathrm{Hb} \%$.

The mean pre $\mathrm{Hb}$ in primi was $9.9 \mathrm{gm} \%$ and in multi was $9.5 \mathrm{gm} \%$. The mean post $\mathrm{Hb}$ in primi was $8.8 \mathrm{gm} \%$ and in multi it was $8.5 \mathrm{gm} \%$.

Table 9 shows that the amount of blood required was very less reflecting the effectiveness of B-Lynch suture in reducing the blood loss. $40 \%$ of the patients required only one pint of blood transfusion and $24 \%$ of patients did not require any blood transfusion at all. Only $14 \%$ of patients had more than 3 pints of blood transfusions.

Table 9: Mean distribution of $\mathrm{Hb}$ values according to gravida.

\begin{tabular}{|lllll|}
\hline \multirow{2}{*}{ Pre $\mathrm{Hb}$} & & N & Mean & SD \\
\cline { 2 - 5 } & Primi & 25 & 9.93 & 0.937 \\
\hline \multirow{2}{*}{ Post $\mathrm{Hb}$} & Multi & 25 & 9.50 & 1.154 \\
\cline { 2 - 5 } & Multi & 25 & 8.79 & 0.798 \\
\hline
\end{tabular}

Table 10: Distribution of blood transfusion.

\begin{tabular}{|lll|}
\hline $\begin{array}{l}\text { No of pints } \\
\text { of blood transfusion }\end{array}$ & Number & Percentage \\
\hline No blood transfusion & 12 & $24 \%$ \\
\hline 1 pint blood transfusion & 20 & $40 \%$ \\
\hline 2 pint blood transfusion & 11 & $22 \%$ \\
\hline$>3$ pint blood transfusion & 7 & $14 \%$ \\
\hline
\end{tabular}

In our study the B-Lynch suture was successful in about $80 \%$ of the cases where hysterectomy was avoided. Hysterectomy was reported as a final procedure in uncontrolled PPH in $18 \%$ of cases and conclusion was not drawn in one case which was settled without B-lynch suture. 
Table 11: Distribution of outcome.

\begin{tabular}{|lll|}
\hline Outcome & Number & Percentage \\
\hline Successful B-Lynch suture & 40 & $80 \%$ \\
\hline Failure(hysterectomy done) & 09 & $18 \%$ \\
\hline Not applicable & 01 & $02 \%$ \\
\hline Total & 50 & $100 \%$ \\
\hline
\end{tabular}

\section{DISCUSSION}

Primary PPH is common obstetric emergency which can lead to emergency hysterectomy in patients with treatment resistant, life threatening bleeding, surgical methods of controlling uterine bleeding by inserting compression sutures have been developed to reduce the incidence of emergency hysterectomy and to preserve future fertility in these patients.

In this study, B-Lynch suture technique for achieving uterine compression in PPH during caesarean section has been achieved. The technique is easy to perform during emergency condition at caesarean section. Furthermore, the procedure prevented emergency post partum hysterectomy in $80 \%$ of cases. The timely application of this suture also reduced the need for blood transfusion and its associated complications.

The mean age in our study was 24 years which is similar to the study of Mohini et al. ${ }^{9}$ The mean gestational age in our study was 37.1 weeks. The mean blood loss was $1495 \mathrm{ml}(800-2500 \mathrm{ml})$.

Table 12: The various parameters of our study compared with other studies.

\begin{tabular}{|c|c|c|c|c|c|c|}
\hline Parameters & Quobha et al ${ }^{6}$ & Hackethal et al ${ }^{10}$ & Koh et $a^{8}$ & Allerhdin et al $^{7}$ & Mohini et al $^{9}$ & Present study \\
\hline Mean age (yrs) & $32(23-40)$ & $32(25-40)$ & $35(33-41)$ & $31(25-38)$ & $29(19-23)$ & 24 \\
\hline $\begin{array}{l}\text { Gestational } \\
\text { age (weeks) }\end{array}$ & 38.7 & 35.4 & 36.8 & 38 & 38 & 37.1 \\
\hline $\begin{array}{l}\text { Blood loss } \\
(\mathrm{ml})\end{array}$ & - & $\begin{array}{l}2500 \\
(2000-3500)\end{array}$ & $\begin{array}{l}2200 \\
(800-5000)\end{array}$ & $\begin{array}{l}3500 \\
(2000-10000)\end{array}$ & - & $\begin{array}{l}1495(800- \\
2500)\end{array}$ \\
\hline $\begin{array}{l}\text { Hb difference } \\
(\mathrm{gm} \%)\end{array}$ & - & 3 gm\% (1.3-5.7) & - & - & $0.8(0.3-1.8)$ & $1.02(0.4-2.2)$ \\
\hline $\begin{array}{l}\text { Baby weight } \\
\text { (kg) }\end{array}$ & - & - & - & $3.5(2.1-4.8)$ & - & $2.6(0.9-4.1)$ \\
\hline Success rate & $95 \%$ & $100 \%$ & $86 \%$ & $72 \%$ & $100 \%$ & $80 \%$ \\
\hline
\end{tabular}

The $\mathrm{Hb}$ difference in our study was $1.02 \mathrm{gm} \%$ which is comparable to original study of Mohini et al $(0.8 \mathrm{gm} \%) .{ }^{9}$ The average birth weight in our study was $2.6 \mathrm{~kg}$ in comparision to $3.5 \mathrm{~kg}$ in original study of Allerhdin et al. ${ }^{7}$

Success rate in our study was $80 \%$ with similar results in original study by Koh et al $(86 \%){ }^{8}$

Quabha et al conducted a review study of all uterine compression sutures for $\mathrm{PPH}$ at one tertiary obstetric hospital. During the 6 years, 20 uterine compression sutures were performed in 31,519 deliveries, 17 at the time of caesarean delivery; 3 after vaginal delivery. Hysterectomy was avoided in $95 \%$ cases. None of the women developed complications related to the procedure. Eight tried to conceive and six women had subsequent uncomplicated pregnancies, thus concluding that uterine compression sutures for severe PPH may obviate the need for hysterectomy and appear not to jeopardize subsequent pregnancy. ${ }^{6}$

Allerhdin et al, conducted a retrospective study on 11 consecutive patients who had undergone B-Lynch suture application during caesarean section as a measure to control atonic PPH. ${ }^{7}$ Patients age, gestational age, blood loss was recorded. Patients were followed up with clinic visits at 6 weeks and whether subsequent successful pregnancies were achieved or not were documented. The mean age was 31 years, mean gestational age was 38 wks. The average blood loss was $3500 \mathrm{ml}$ and hysterectomy was needed only in 3 patients accounting to $72 \%$ success rate. $^{7}$

Koh et al, conducted a retrospective study on women who had undergone the B-Lynch procedure. The mean age in their study was 35 years and average gestational age was 37 weeks. The average blood loss was $2200 \mathrm{ml} \mathrm{(400-}$ $5000 \mathrm{ml}$ range). The B-Lynch procedure failed to control bleeding in 2 cases accounting to a success rate of $86 \%$. There were no known immediate or long-term complications. $^{8}$

Mohini et al conducted a pilot study to evaluate the effect of elective B-Lynch suture in preventing atonic $\mathrm{PPH}$ during emergency caesarean section. The mean age in this study was 20 years and average gestational age was 38 weeks. None of the women required blood transfusion or additional pharmacological intervention. No intraoperative or postoperative or six-month follow up complications were noted. In conclusion elective BLynch suture is cheap, quick and appeared to be effective in preventing atonic PPH in women undergoing 
emergency LSCS with high risk factors for atonic PPH. ${ }^{9}$ Hackethal et al, conducted a prospective study to evaluate the effectiveness of a modified U-suturing technique in uterine compression, in patients with primary $\mathrm{PPH}$ after caesarean section. The mean age in this study was 32 years and average gestational age was 35.4 weeks. Average blood loss was $2500 \mathrm{ml}$ (2000-3500ml range). Success rate was $100 \%$ thus proving that this technique is highly effective and straight forward emergency procedure which conserves uterus in patients with atonic PPH. ${ }^{10}$

\section{CONCLUSION}

Present study showed cases treated with B-Lynch procedure showed that it is an effective method of containing pph. It has the advantage of being applied easily and safely. It should be attempted when conservative management fails and before any radical surgery is considered.

\section{Funding: No funding sources}

Conflict of interest: None declared

Ethical approval: The study was approved by the Institutional Ethics Committee

\section{REFERENCES}

1. Arulkumarn S. Onning Tanizian: The management of post partumhaemorrage; in arulkumarns; The management of labour. $2^{\text {nd }}$ Edition. 2006;208-228.

2. Dutta DC. Complication of third stage of labour: Text book of Obstetrics: $6^{\text {th }}$ edition. 2004;411-418.
3. Combs CA, Murphy E, Larv RK. Factors associated with post partumhaemorrage with vaginal birth. Obstet Gynecol. 1991:77:69-76.

4. Drief J. Management of primary post partumhaemorrage. Br. J. Obstet Gynecol. 1997;104:275-7.

5. Registrar General of India in health information, India. Ministry of Health. New Delhi. 2008.

6. Quahba J, Picketty M, AZarian M. Uterine compression sutures for post partum bleeding with uterine atony. BJOG. 2007;114(5);619-22.

7. Allerhdin S, Aird C, Darielian P. B-Lynch sutures for major primary PPH at caesarean delivery. Obstet Gynecol. 2006;26(7).

8. Koh E, Devendra K, Tan LH. B-Lynch suture for the treatment of uterine atony. Singapore Med J. 2009;50(7):693-97.

9. Vachhani M, Virkud A. Prophylactic B-Lynch suturing in emergency caesarean section in women at high risk of uterine atony: A pilot study. The Internet Journal of Gynecology and Obstetrics. 2007;7(1):18.

10. Hackethal A, Bruggmann D, Oehmke F, Tinneberg HR. Uterine compression U sutures in primary PPH after caesarean section: Fertility preservation with a simple and effective technique. Human Reproduction. 2008;23(1):74-9.

Cite this article as: Sudha HC, Pairu J, Kamalakshi. B-lynch suture in the management of uterine atony during caesarean section. Int J Reprod Contracept Obstet Gynecol 2019;8:1946-50. 